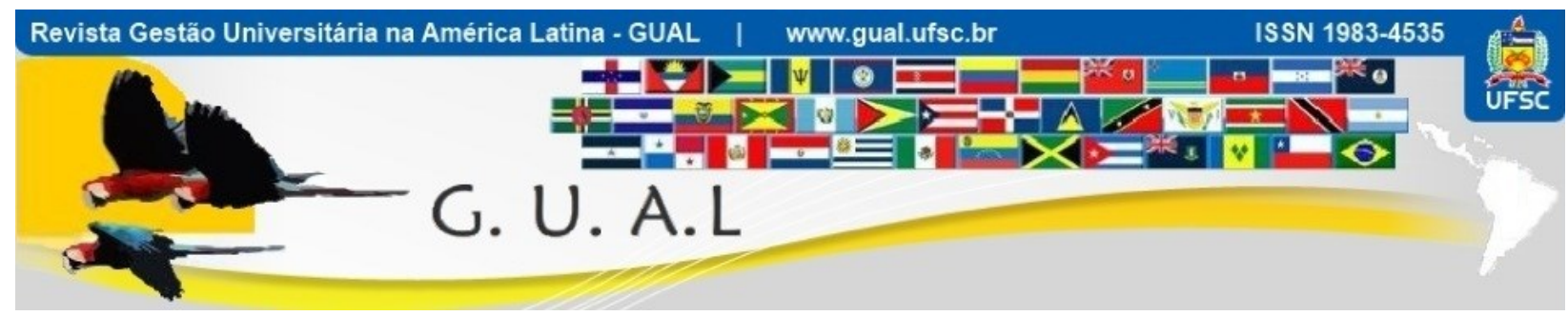

DOI: http://dx.doi.org/10.5007/1983-4535.2013v6n3p190

\title{
UMA AVALIAÇÃO DOS CONHECIMENTOS NECESSÁRIOS, ADQUIRIDOS E UTILIZADOS PELOS EGRESSOS DO CURSO DE ADMINISTRAÇÃO
}

\section{AN ASSESSMENT OF KNOWLEDGE REQUIRED ACQUIRED AND USED BY ADMINISTRATION STUDENTS}

Fernanda Rosalina Silva Meireles, Mestranda Universidade Federal do Ceará - UFC nandacmdm@hotmail.com

Ana Rita Pinheiro Freitas, Mestranda Universidade Federal do Ceará- UFC anarita1802@hotmail.com

Mônica Cavalcanti Sá Abreu, Doutora Universidade Federal do Ceará - UFC mabreu@ufc.br

Sílvia Maria Dias Pedro Rebouças, Doutora Universidade Federal do Ceará- UFC smdpedro@gmail.com

Recebido em 24/abril/2013

Aprovado em 08/agosto/2013

Sistema de Avaliação: Double Blind Review

Esta obra está sob uma Licença Creative Commons Atribuição-Uso. 


\title{
RESUMO
}

Este estudo tem como objetivo analisar a percepção dos egressos do curso de Administração em relação à importância, absorção e utilização de conhecimentos considerados necessários à formação do administrador. Três construtos foram analisados: importância dos temas tratados para a formação do administrador, absorção dos conhecimentos adquiridos pelos egressos no curso, e, utilização dos conhecimentos abordados. Os temas considerados dizem respeito a disciplinas ministradas na grade curricular do curso de graduação em Administração da Universidade Federal do Ceará e outros conhecimentos listados por egressos do curso em workshop realizado na primeira etapa da pesquisa. A segunda etapa do estudo consistiu na aplicação de um questionário a 115 egressos do curso, para verificar a percepção destes em relação aos temas tratados. A análise dos dados incluiu o cálculo e comparação de médias, o escalonamento multidimensional replicado e a análise de agrupamentos. Os resultados da pesquisa apontam que os conhecimentos considerados menos importantes pelos egressos são também conhecimentos que os mesmos menos utilizam - Cálculo e Saúde e Segurança. Percebe-se uma carência de algumas disciplinas consideradas importantes na grade curricular do curso na universidade, como Negócios internacionais, Ética e Negociação.

Palavras-chave: Administração. Avaliação de Egressos. Ensino de Administração. Gestão Universitária. Avaliação Curricular.

\begin{abstract}
This study aims to analyze the perceptions of students who graduated from Administration regarding the importance, absorption and utilization of knowledge deemed necessary for the formation of the administrator. Three constructs were analyzed: the importance of the topics discussed for the formation of the administrator, absorption of knowledge acquired by graduates in the course, and use of knowledge covered. The issues considered concern courses taught in the curriculum of undergraduate degree in Business Administration at the Federal University of Ceara and other skills listed by graduates of the course in a workshop held in the first stage of the research. The second stage of the study consisted of a questionnaire with 115 graduates of the course to verify the perception in relation to these themes. Data analysis included calculation and comparison of means, replicated multidimensional scaling and cluster analysis. The results indicate that the skills considered less important by graduates are also they use less - Calculus and Health and Safety. We can see a lack of some subjects considered important in the curriculum of the course at the university, such as international business, ethics and negotiation.
\end{abstract}

Keywords: Business. Alumni. Knowledge Assessment. Business Teaching. Curriculum. 


\section{INTRODUÇÃO}

O mundo corporativo passa por profundas mudanças no mercado atual. Questões como a gestão do conhecimento, gestão de projetos, inovação tecnológica, internacionalização, responsabilidade social corporativa e mudanças climáticas são cada vez mais preocupantes para as empresas. A globalização rompeu quase todas as barreiras e o mundo tornou-se muito mais dinâmico. A Administração, assim como as demais ciências, sente a necessidade de se reinventar.

Nesse contexto, afirmam Araújo e Correia (2001), recai sobre as universidades a responsabilidade de associar ao processo de ensino-aprendizagem não apenas os conhecimentos que o aluno deve obter de um conjunto de disciplinas, mas quais atitudes ele deve adotar, e que desempenhos será capaz de executar com o desenvolvimento de habilidades. A universidade deve buscar formas mais flexíveis de organização dos cursos e carreiras, permitindo a interconexão e o enriquecimento de ambos (SOBRINHO, 2000). Desta forma, torna-se fundamental avaliar a adequação entre os conhecimentos adquiridos pelos egressos do curso de Administração e o mercado. Kitahara et al (2007) asseveram que as mudanças na sociedade, como o surgimento de novos setores, novas tecnologias, novas formas de emprego, e a mudanças na forma de pensamento, são imperativos aos quais o currículo universitário deve se adaptar. Por consequência, o currículo da graduação de Administração tem passado por modificações, visando adaptar-se às necessidades do mercado e às exigências dos profissionais egressos.

Assim, este trabalho busca responder ao seguinte questionamento: Quais os conhecimentos considerados necessários, na percepção dos egressos, à formação do administrador? Portanto, tem-se como objetivo geral analisar a percepção dos egressos do curso de Administração em relação à importância, absorção e utilização de determinados conhecimentos considerados necessários à formação do administrador. Diante deste, tem-se como objetivos específicos: a) identificar a percepção dos egressos quanto à importância dos conhecimentos de Administração; b) identificar a percepção dos egressos quanto à absorção dos conhecimentos de Administração; c) identificar a percepção dos egressos quanto à utilização dos conhecimentos de Administração; d) identificar as semelhanças e diferenças entre os conhecimentos quanto a sua importância, absorção e utilização; e) identificar grupos de conhecimentos, com semelhanças, na opinião dos egressos, no que diz respeito a sua importância, absorção e utilização. 
O presente estudo se justifica pela necessidade de averiguar qual a percepção dos egressos sobre os conhecimentos considerados necessários à formação do administrador. A partir da análise estatística, se buscará encontrar grupos de conhecimentos classificados de acordo com a percepção dos egressos sobre a sua importância, absorção e utilização. Vários artigos de grande interesse acadêmico foram produzidos visando identificar variáveis relacionadas ao ensino de Administração (COSTA, PEREIRA e SOLINO, 2001; GODOY et al., 2006; BOMTEMPO et al, 2007; KITAHARA et al, 2007; ALVARÃES, 2009; DIAS, 2009; MARANHÃO e DE PAULA, 2009; SOUZA e REINERT, 2009). Entretanto, dentre todas essas pesquisas, somente um debate acerca dos conhecimentos necessários à formação do administrador, motivo pelo qual se considera relevante esta pesquisa.

\section{MARCO TEÓRICO}

\subsection{O ENSINO DE ADMINISTRAÇÃO NO BRASIL E TRABALHOS EMPÍRICOS}

A história dos cursos superiores de Administração no Brasil, de acordo com Silva e Fischer (2008), começa no início do século XX, marcada por um longo processo de definição sobre quais as fronteiras do campo do saber administrativo, sendo seu ensino, durante mais de seis décadas, confundido com o das Ciências Econômicas, até a definição do currículo mínimo em 1966. Segundo o CFA (2011), o ensino da Administração no Brasil teve seus primórdios na década de 30, tendo como embrião o Instituto de Organização Racional do Trabalho (IDORT), fundado em 23 de junho de 1931, por iniciativa de Armando Sales de Oliveira. Em 1938, o Governo, sob a coordenação de Luiz Simões Lopes, criou o Departamento Administrativo do Serviço Público (DASP), que enviava seus primeiros Técnicos de Administração para aperfeiçoamento no exterior. Em 1944, ainda sob a orientação de Luiz Simões Lopes, foi fundada a Fundação Getúlio Vargas, umas das escolas mais antigas de Administração do Brasil.

O processo de formação do administrador profisssional, no sistema educacional brasileiro, acentuou-se com a regulamentação da profissão, ocorrida em 9 de setembro de 1965, através da Lei no 4.769 (CFA, 2011). Tal lei delimitou o acesso ao mercado profissional somente aos portadores de títulos expedidos pelo sistema universitário. No ano seguinte, pelo Parecer $n^{0} 307 / 66$, foi definido, pelo Conselho Federal de Educação, o primeiro currículo mínimo do curso de Administração, institucionalizando assim a profissão no Brasil.

Analisando a evolução do curso de Administração no Brasil, desde sua criação até a 
década de 1990, Nicolini (2003) destaca que as primeiras décadas do curso no país (1930 ao final de 1950) foram marcadas pelo currículo voltado à racionalização e ao uso extensivo de modelos estrangeiros. Já nas décadas de 1960 e 1970, inicia-se o período de expansão do curso e desvinculação da pesquisa, marcado pela regulamentação do ensino de Administração, e pela grande procura por profissionais da área, devido ao período de "milagre econômico" brasileiro, voltando-se os administradores para o mercado. Em 1982, é constituído um Grupo de Trabalho pela Secretaria de Ensino Superior, que gera anteprojeto de Reformulação Curricular dos Cursos de Administração, projeto esse que só vem a ser discutido e implementado na década de 1990. Apesar das mudanças pelas quais o curso de Administração passou, Skora e Mendes (2001) descrevem que, da década de 1990 até aos dias atuais, a formação do administrador encontra-se regulamentada pelos critérios definidos há três décadas.

Maciel, Hocayen-da-Silva e Castro (2008) asseveram que, mesmo que relativamente recente, nas décadas que se seguiram à instituição e desenvolvimento do curso no Brasil, nota-se uma constante preocupação com a qualidade do ensino superior em Administração e com a formação do administrador. Discute-se que, a partir de meados dos anos 1990, os cursos de graduação em Administração tiveram um crescimento exponencial em oferta, não sendo tal crescimento acompanhado por uma melhor qualidade do ensino destes. Os autores afirmam que tal problema é estrutural, tendo como possível razão a falta de prestígio e identidade do curso, na sua implantação no país.

\subsection{CURRÍCULO DE CURSOS DO ENSINO SUPERIOR}

O currículo, dentre outros mecanismos, é considerado um elemento fundamental para a formação adequada do administrador. De acordo com o MEC (2006a), o currículo é um instrumento de grande importância, formado por um conjunto de elementos do processo de ensino-aprendizagem num determinado tempo e contexto. É instituído como um ambiente para formação dinâmica, diversificada e multicultural, onde os resultados do processo de avaliação são perspectivas importantes a serem consideradas no seu aperfeiçoamento.

Moreira e Silva (1999) ampliam a discussão sobre currículo, afirmando que este é uma área contestada, uma arena política e de poder, e que por isso faz-se importante conhecer a história da produção do currículo. Os currículos dos cursos da formação profisssional são estruturas representativas de estruturas mais profundas do conhecimento (FISCHER, 2003). 


\begin{abstract}
Entende-se por currículo de um curso de formação profissional o conjunto de matérias, modos e meios de ensino aprendizagem, decorrentes do contexto cultural e de natureza do conhecimento envolvido, que assumam configurações de disciplinas e de articulações disciplinares, a serem desenvolvidas, cooperativamente, por professores e alunos, visando o desenvolvimento da competência socialmente desejável para o exercício de uma profissão. (FISCHER, 2003, p.49).
\end{abstract}

Na visão de Alves e Reinert (2007), os currículos brasileiros parecem ser constituídos, muitas vezes, por programas isolados e incomunicáveis, que produzem uma formação insuficiente para o enfrentamento das práticas sociais, que exigem algo mais crítico. Macedo (2002) destaca que a vigente organização do currículo, focada na ideologia da racionalidade técnica, trata o conhecimento como um produto atomizável e objetivo, renunciando assim da compreensão de currículo como cultura. Desta forma, o currículo é assumido como produto, e homogeneamente aplicado a diferentes grupos.

Focando-se no currículo do curso de graduação em Administração, conforme Silva e Fischer (2008), no Brasil, este passou por três momentos de aprovação de currículos mínimos do curso: 1966, com a aprovação de seu primeiro currículo, que fixou o conteúdo mínimo e a duração do curso, e instruiu as escolas por quase trinta anos; 1993, com a reformulação do currículo mínimo, visando ajustar a formação do administrador ao avanço das ciências e tecnologia, deu também oportunidade às instituições para criar habilitações, contribuindo para a formação específica do administrador; 2003, com homologação das Diretrizes Curriculares Nacionais, e aprovação, em 2004, das diretrizes curriculares para os cursos de graduação em Administração, permitindo a revisão, análise e implementação de um Projeto Pedagógico que buscasse melhores níveis de qualidade, competitividade e legitimidade.

Prestes Motta (1983) argumenta que um dos principais problemas das faculdades de Administração brasileiras, resultante da estrutura universitária nacional, é a pouca ênfase em análises críticas da realidade, problema esse advindo do isolamento de especialistas. Os programas brasileiros não estão aptos para preparar os estudantes de Administração para questões que enfrentam hoje e enfrentarão em um futuro próximo, estando, a maioria dos cursos, preparando-os para problemas de ontem. Argumenta-se que os principais problemas dos programas de Administração brasileiros são: ausência de tópicos vinculados à dimensão internacional da Administração, pouco tratamento de questões relativas à moeda e crédito (tanto nacionais quanto internacionais), atenção insuficiente aos problemas das empresas estatais, exame insuficiente de questões voltadas à tecnologia no curso, e lacuna quanto à gestão de pequenas e médias empresas. 
Aktouf (2005, p.152) critica três características dominantes do ensino de Administração, e defende a mudança radical destas. São elas: “(a) a definição restrita de Administração centrada na predominância do fator capital e na preocupação do enriquecimento individual; (b) a onipresença dos aspectos quantitativos, em particular a do cálculo econômico; e (c) a falta de cultura geral na formação de Administração". Perpetua-se, portanto, um ensino voltado para a reprodução, ao invés da mudança.

Assim, Saviani (1994) defende uma visão de integração do conhecimento, dada pela interdisciplinaridade, criando uma nova disposição não só das disciplinas, mas também dos temas e unidades de uma disciplina, na busca de se evitar a fragmentação do conhecimento. A Universidade deve oferecer uma gama diversificada de disciplinas, buscando assim se aproximar mais do ideal de formação, através de propostas curriculares que apresentassem interação com Departamentos de Ensino diferentes daquele ao qual o curso deveria estar mais intimamente ligado (ALVES; REINERT, 2007).

\subsection{AVALIAÇÃO DE CURRÍCULO DE CURSOS DO ENSINO SUPERIOR}

A avaliação dos currículos dos cursos de ensino superior, no Brasil, é realizada através do Sistema Nacional de Avaliação da Educação Superior (SINAES). Dentro do processo de avaliação dos cursos de graduação, o currículo encontra-se como elemento constitutivo do Projeto Pedagógico do Curso (PPC), que é um dos três pilares da a serem avaliados pelo SINAES, juntamente com o Projeto Pedagógico Institucional (PPI) e o Plano de Desenvolvimento Institucional (PDI), especificando o posicionamento da Instituição de Ensino Superior sobre a educação, sociedade e ser humano, tendo caráter de instrumentos de ação pedagógica e política (MEC, 2006b).

A Comissão de Avaliação do Curso designada avalia os seguintes indicadores curriculares (MEC, 2006b, p.16): a) Coerência do currículo com os objetivos do curso; b) Coerência do currículo com o perfil desejado do egresso; c) Coerência do currículo face às diretrizes curriculares nacionais (indicador imprescindível); d) Adequação da metodologia de ensino à concepção do curso; e) Inter-relação das unidades de estudo na concepção e execução do currículo; f) Dimensionamento da carga horária das unidades de estudo; g) Adequação e atualização das ementas e programas das unidades de estudo; h) Adequação e atualização da bibliografia; i) Coerência do corpo docente e corpo técnico-administrativo com a proposta curricular; j) Coerência dos recursos materiais específicos do curso (laboratórios e 
instalações específicas, equipamentos e materiais) com a proposta curricular; k) Estratégias de flexibilização curricular. Tais indicadores são avaliados através de uma escala de 1 a 5 , onde 5 representa o conceito máximo.

\section{METODOLOGIA}

Esta pesquisa caracteriza-se como um estudo exploratório e descritivo, pois objetiva descrever a percepção de egressos do curso de Administração acerca de temas considerados necessários à formação do administrador. De acordo com Sampieri, Collado e Lucio (2006), pesquisas exploratórias visam examinar um tema ou problema de pesquisa pouco estudado, caso do tema desta pesquisa. Já os estudos descritivos, afirmam Cooper e Schindler (2003), buscam descrever ou definir um assunto através da criação de um perfil para um grupo de problemas, pessoas ou eventos.

Quanto à abordagem, o artigo classifica-se em quantitativo, visto que visa apresentar a percepção de egressos do curso de Administração através de análise estatística de dados coletados por aplicação de um questionário. $\mathrm{O}$ enfoque quantitativo confia na medição numérica e no uso da estatística, para demonstrar com exatidão os padrões de comportamento de uma população (SAMPIERI; COLLADO; LUCIO, 2006).

A coleta de dados deu-se através de dados primários, por meio de survey eletrônica construída em website e enviada por e-mail. A população desta pesquisa corresponde aos egressos do curso de Administração da Universidade Federal do Ceará. Nesse sentido foram coletados dados de 115 egressos do curso de forma independente ao ano no qual se formou. A amostra possui alunos formados desde 2002 ao primeiro semestre de 2011. Os questionários foram respondidos entre setembro de 2009 e novembro de 2010. Os dados coletados foram tabulados e analisados por meio do software estatístico Statistical Package for the Social Sciences (SPSS) em sua versão 20.0.

A pesquisa foi realizada em duas etapas. Na primeira etapa da pesquisa foi realizado um workshop em 2009 com egressos do curso de Administração da UFC a fim de construir o instrumento de coleta de dados com os conhecimentos considerados por estes necessários à formação do administrador. Dos conhecimentos listados, a maioria faz parte da grade curricular do curso de Administração ministrado pela universidade, entretanto, outros conhecimentos também foram listados. 
A partir do workshop, foi desenvolvido o instrumento de coleta com três construtos principais: a importância dos temas tratados para formação do administrador, o grau absorção dos conhecimentos adquiridos pelo egresso de Administração no seu curso acerca dos temas expostos, e, a utilização dos conhecimentos tratados. Ao final, foram definidos 27 conhecimentos: Administração da Produção, Administração de Materiais, Administração Geral, Cálculo, Contabilidade de Custos, Direito, Empreendedorismo, Estatística, Estratégia e Planejamento, Ética, Finanças, Gestão Ambiental, Gestão de Conflitos, Gestão de Projetos, Gestão Tributária, Inglês (ou outro idioma), Logística, Marketing, Negociação, Negócios Internacionais, Pesquisa Operacional, Plano de Negócios, Processo Administrativo, Recursos Humanos, Responsabilidade Social, Saúde e Segurança no Trabalho, Tecnologia da Informação.

A segunda etapa do estudo consistiu na aplicação dos questionários com 115 egressos do curso de Administração da UFC para verificar a percepção destes em relação aos conhecimentos considerados necessários à formação do administrador. Foram utilizadas perguntas em forma de escala de Likert de cinco pontos em relação à importância dos conhecimentos listados, a absorção dos conhecimentos pelos egressos e a utilização dos conhecimentos. Foi analisado ainda o perfil dos respondentes, com questões relacionadas a sexo, idade, área de trabalho, cargo ocupado, faixa de salário e ano de conclusão do curso.

Por fim, as semelhanças entre os conhecimentos no que diz respeito à importância, absorção e aplicação, na percepção dos egressos, foram avaliadas por escalonamento multidimensional replicado, com recurso ao algoritmo PROXSCAL implementado no SPSS. O escalonamento multidimensional é uma técnica exploratória multivariada, que permite representar de forma parcimoniosa, e num sistema dimensional reduzido, as proximidades entre objetos, a partir de um conjunto de atributos medidos ou percepcionados (MAROCO, 2007).

No escalonamento multidimensional clássico, os dados consistem numa matriz de proximidades. Neste artigo, a técnica foi aplicada aos dados em bruto, tendo sido calculada diretamente pelo algoritmo implementado no SPSS, para cada egresso, uma matriz de proximidades entre conhecimentos. Uma vez que se dispõe da percepção de uma amostra de 115 egressos, aplicou-se o escalonamento multidimensional replicado, que permite utilizar várias matrizes de proximidades, uma para cada egresso, em simultâneo. 
A partir da representação dos conhecimentos num mapa perceptual num mapa perceptual obtido pelo escalonamento multidimensional, aplicou-se o método hierárquico de análise de agrupamentos ou conglomerados. Este método permite agrupar casos ou variáveis, neste caso, os conhecimentos, em grupos homogêneos em função do seu grau de similaridade (MAROCO, 2007). A medida utilizada para avaliar a similaridade entre os conhecimentos foi o quadrado da distância euclidiana e o método utilizado para o cálculo da distância entre agrupamentos foi o da distância média.

\section{ANÁLISE DOS RESULTADOS}

Os resultados abaixo apresentados descrevem, primeiramente, o perfil dos respondentes da pesquisa. Em seguida, parte-se para a análise da importância, absorção e utilização dos conhecimentos, através cálculo e comparação de médias, o escalonamento multidimensional replicado e a análise de agrupamentos.

\subsection{PERFIL DOS RESPONDENTES}

Dos 115 pesquisados, a maioria é do sexo masculino correspondendo a $63,5 \%$ da amostra, enquanto que as mulheres correspondem a $36,5 \%$ da amostra. Na amostra analisada, verificou-se que os homens possuem salários mais altos que as mulheres. Verifica-se na Tabela 1 que 94,1\% das mulheres entrevistadas possuem faixa salarial de zero a oito salários mínimos, sendo que mais da metade das entrevistadas $(55,9 \%)$ recebem somente até três salários. Dos homens, este percentual é menor, 35\% recebem até três salários e 86,7\% recebem de zero a oito salários.

Tabela 1 Faixa salarial e sexo dos respondentes da pesquisa

\begin{tabular}{|c|c|c|c|c|}
\hline & & \multicolumn{2}{|c|}{ Sexo } & \multirow[b]{2}{*}{ Total } \\
\hline & & Feminino & Masculino & \\
\hline \multirow{5}{*}{$\begin{array}{l}\text { Faixa } \\
\text { Salarial }\end{array}$} & 0 - 3 Salários Mínimos & $55,9 \%$ & $35 \%$ & $42,6 \%$ \\
\hline & 4 - 8 Salários Mínimos & $38,2 \%$ & $51,7 \%$ & $46,8 \%$ \\
\hline & 9 -11 Salários Mínimos & $2,9 \%$ & $8,3 \%$ & $6,4 \%$ \\
\hline & 12 -15 Salários Mínimos & $2,9 \%$ & $1,7 \%$ & $2,1 \%$ \\
\hline & Acima de 20 Salários Mínimos & 0 & $3,3 \%$ & $2,1 \%$ \\
\hline Total & & $100 \%$ & $100 \%$ & $100 \%$ \\
\hline
\end{tabular}

Fonte Elaborado pelos autores, a partir dos dados coletados na pesquisa de campo.

Observa-se que a maioria dos egressos pesquisados atua na área em que se formaram, 82,6\% da amostra afirmou trabalhar na área de Administração. As principais áreas de atuação mencionadas pelos pesquisados dizem respeito às áreas: Administrativo (17,4\%), Finanças 
(9,6\%), Marketing e Administração Pública (7\%). O Gráfico 1 apresenta a análise descritiva nas áreas de atuação dos egressos pesquisados.

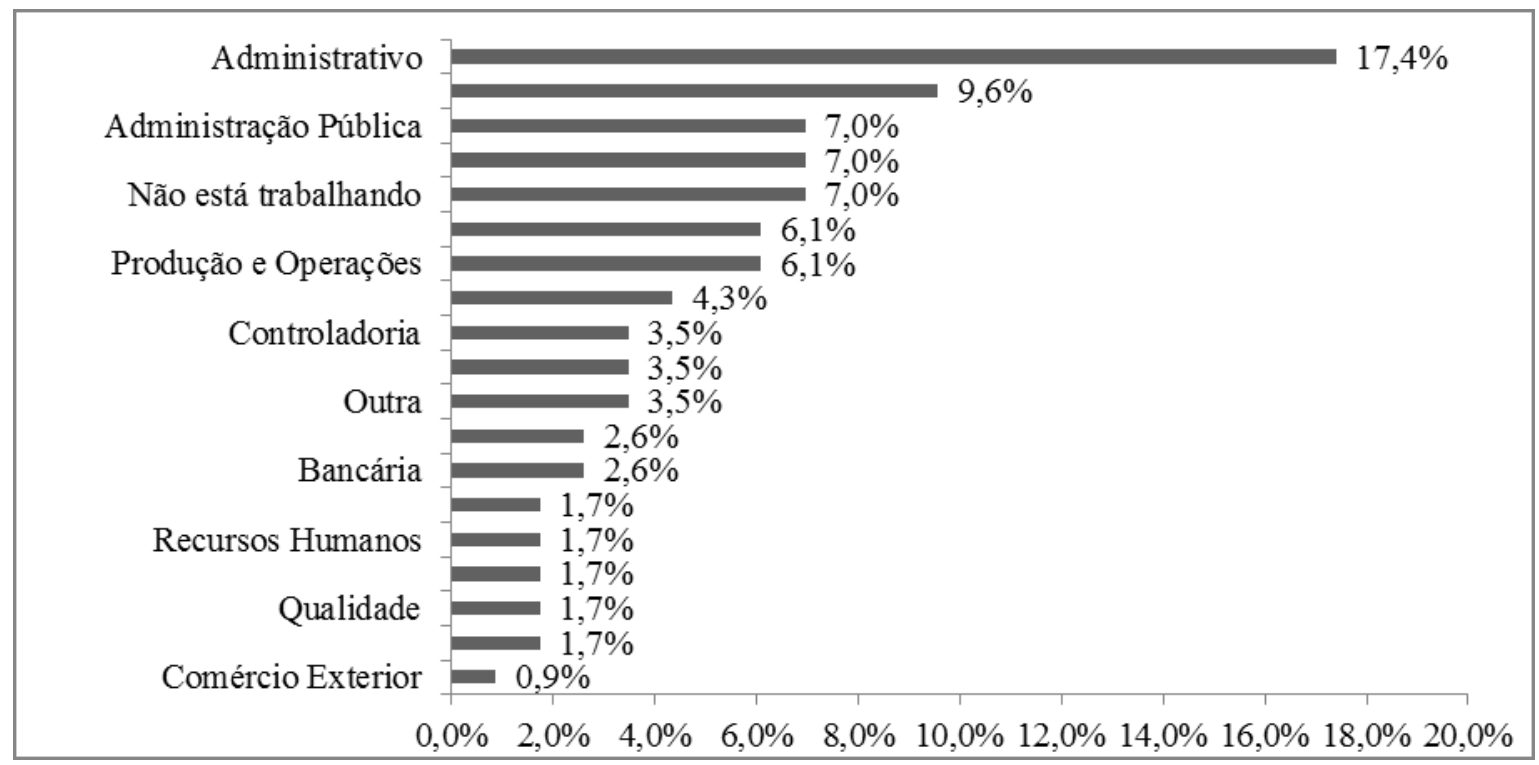

Gráfico 1 Análise descritiva nas áreas de atuação dos egressos pesquisados.

Fonte: Elaborado pelos autores, a partir dos dados coletados na pesquisa de campo.

A média de idade dos egressos pesquisados é de 26 anos e meio, variando de 21 a 45 anos, com desvio padrão de 3,95. Mais da metade dos respondentes possuem de 21 a 25 anos (50,4\%), 37,4\% dos respondentes possuem de 26 a 30 anos, $8,7 \%$ possuem de 31 a 35 anos, e $3.4 \%$ possuem de 36 a 45 anos.

\subsection{IMPORTÂNCIA, ABSORÇÃO E UTILIZAÇÃO DOS CONHECIMENTOS}

As perguntas referentes à importância dos conhecimentos listados, a absorção dos conhecimentos pelos egressos e à utilização dos conhecimentos permitiram verificar quais conhecimentos são considerados importantes pelos egressos numa escala de 1 a 5 , variando de sem importância a muito importante, o grau de conhecimento do respondente, variando de péssimo a ótimo, e a utilização dos conhecimentos propostos, variando de nunca a sempre.

O Gráfico 2 permite visualizar os conhecimentos considerados menos importantes como Cálculo e Saúde e Segurança no Trabalho, os menos absorvidos como Saúde e Segurança, Gestão de Conflitos, Negócios Internacionais, Gestão Tributária, Gestão Ambiental e Línguas Estrangeiras e os menos utilizados: Cálculo, Gestão Ambiental, Saúde e Segurança. 


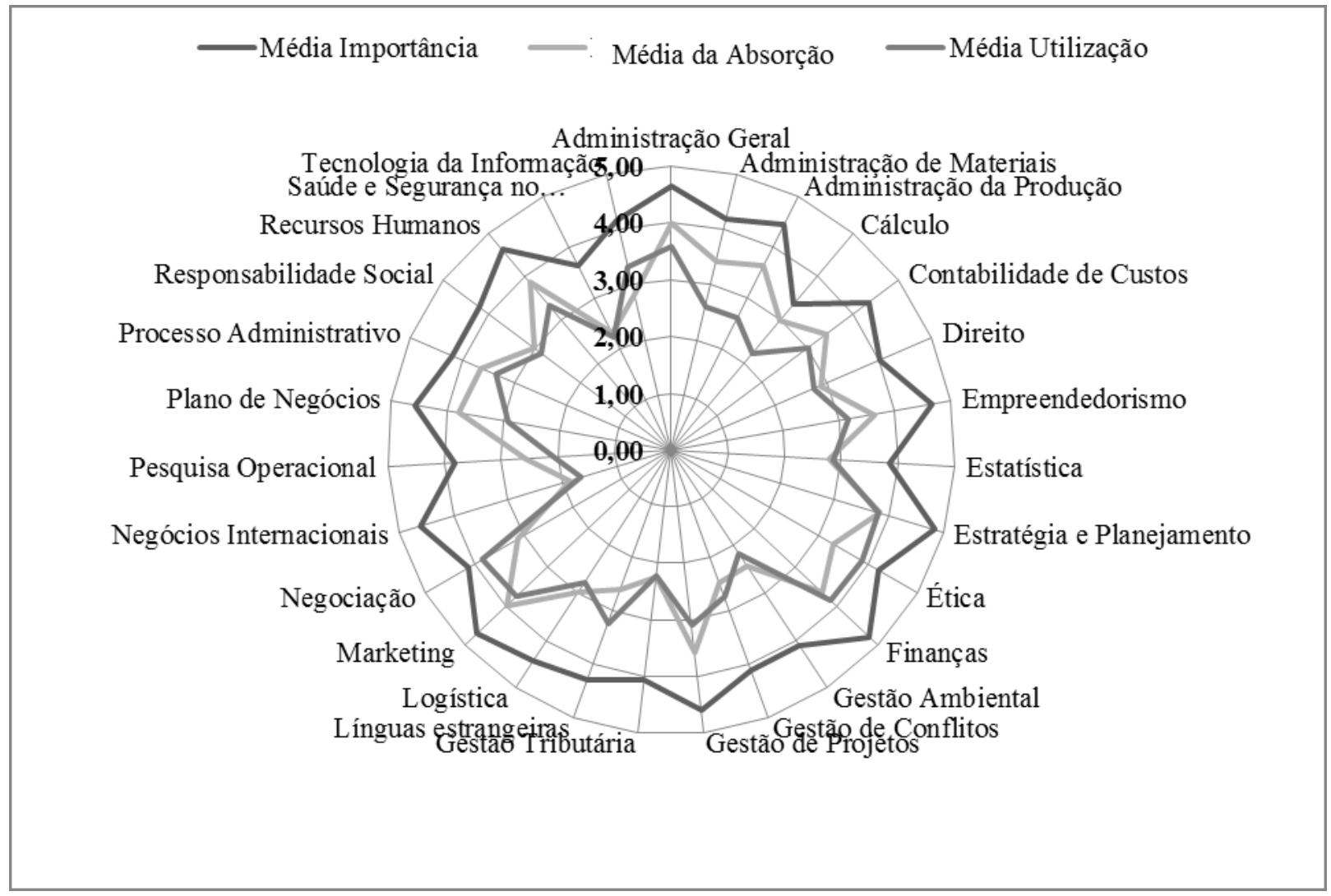

Gráfico 2 Radar: Médias da importância, da absorção e da utilização dos conhecimentos Fonte: Elaborado pelos autores, a partir dos dados coletados na pesquisa de campo.

Os conhecimentos considerados menos importantes pelos egressos são também conhecimentos que os mesmos menos utilizam - Cálculo e Saúde e Segurança. Saúde e Segurança no Trabalho também foi considerado um dos conhecimentos menos absorvidos pelos egressos em sua graduação. Destaca-se que esse conhecimento não existe como disciplina na Universidade Federal do Ceará, sendo até desconhecido por alguns pesquisados. Já para o conhecimento de Cálculo, existem duas disciplinas na Instituição de Ensino pesquisada, o que justifica o fato deste conhecimento não ter sido considerado como pouco conhecido. Embora considerado quase indiferente para os egressos pesquisados.

Os conhecimentos menos absorvidos pelos egressos dizem respeitos a conhecimentos não existentes como disciplinas na graduação dos pesquisados. Entretanto, com exceção de Saúde e Segurança, estes conhecimentos foram considerados importantes para a formação do administrador. São eles: Negociação, Negócios Internacionais, Gestão Ambiental, Responsabilidade Social, Gestão de Conflitos e Gestão Tributária. Nesse sentido, pode-se refletir em relação à inserção destes conhecimentos na grade curricular do curso. 
Para melhor análise descritiva dos construtos foi realizada as seguintes observações por meio de gráficos X Y: a importância dos conhecimentos e o grau de absorção dos conhecimentos, a importância dos conhecimentos e sua utilização pelos egressos, e o grau de conhecimento e sua utilização pelos egressos.

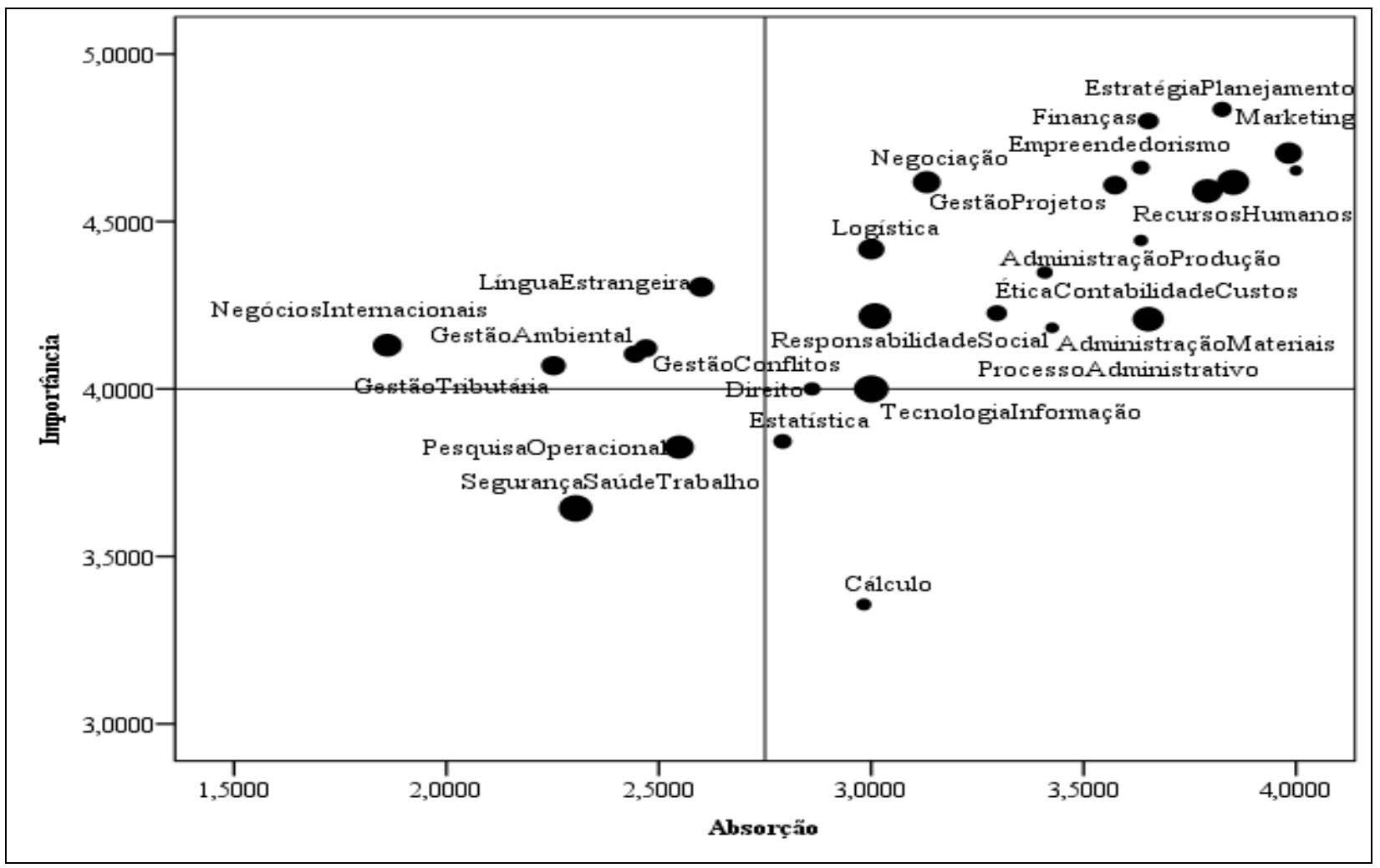

Gráfico 3 Absorção e importância média dos conhecimentos

Fonte: Elaborado pelos autores com os dados coletados na pesquisa de campo.

Em relação à importância e à absorção dos conhecimentos, o Gráfico 3 permite verificar que os conhecimentos considerados mais importantes e mais absorvidos pelos egressos são: Estratégia e Planejamento, Finanças, Marketing, Administração Geral, Recursos Humanos, Plano de Negócios, Administração da Produção e Processo Administrativo. O conhecimento considerado mais importante e menos absorvido foi Negócios Internacionais. O conhecimento considerado menos importante e mais absorvido foi Cálculo e o conhecimento menos importante e menos absorvido foi Saúde e Segurança.

Com relação à análise entre importância e utilização, conforme Gráfico 4, foi verificado que os conhecimentos mais importantes e mais utilizados são Finanças, Estratégia e Planejamento, Marketing, Administração Geral, Ética e Negociação. Os conhecimentos mais importantes e menos utilizados foram Negócios Internacionais, Gestão Ambiental e Gestão 
Tributária. O conhecimento considerado menos importante e mais utilizado foi Estatística e o conhecimento menos importante e menos utilizado foi Cálculo.

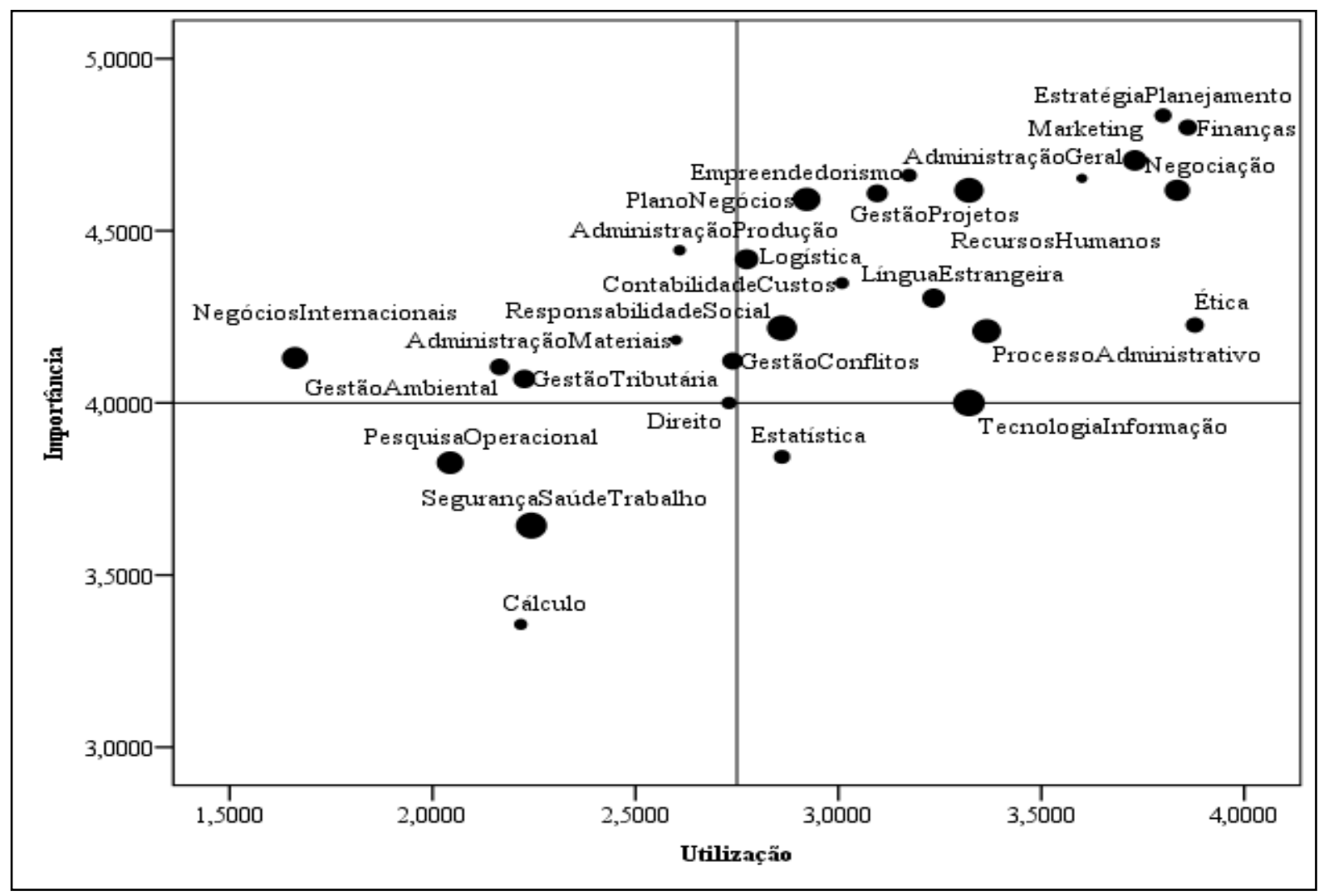

Gráfico 4 Utilização e importância média dos conhecimentos

Fonte: Elaborado pelos autores, a partir dos dados coletados na pesquisa de campo.

O Gráfico 5 apresenta a análise entre a absorção dos conhecimentos e a sua utilização. Evidencia-se que os conhecimentos mais absorvidos na graduação na IES pesquisada e mais utilizados foram Marketing, Estratégia e Planejamento, Administração Geral e Finanças. Os conhecimentos mais absorvidos e menos utilizados foram Administração da Produção e Administração de Materiais. O conhecimento menos absorvido e mais utilizado foi Línguas Estrangeiras, e os menos absorvidos e menos utilizados foram Negócios Internacionais, Pesquisa Operacional, Gestão Ambiental, Gestão Tributária e Saúde e Segurança.

Através das análises descritivas notaram-se convergências nos resultados entre algumas disciplinas. Dessa forma, aplicou-se análise fatorial por componentes principais nos construtos verificados (importância, absorção do conhecimento e utilização) a fim de verificar como estes construtos poderiam ser agrupados. 


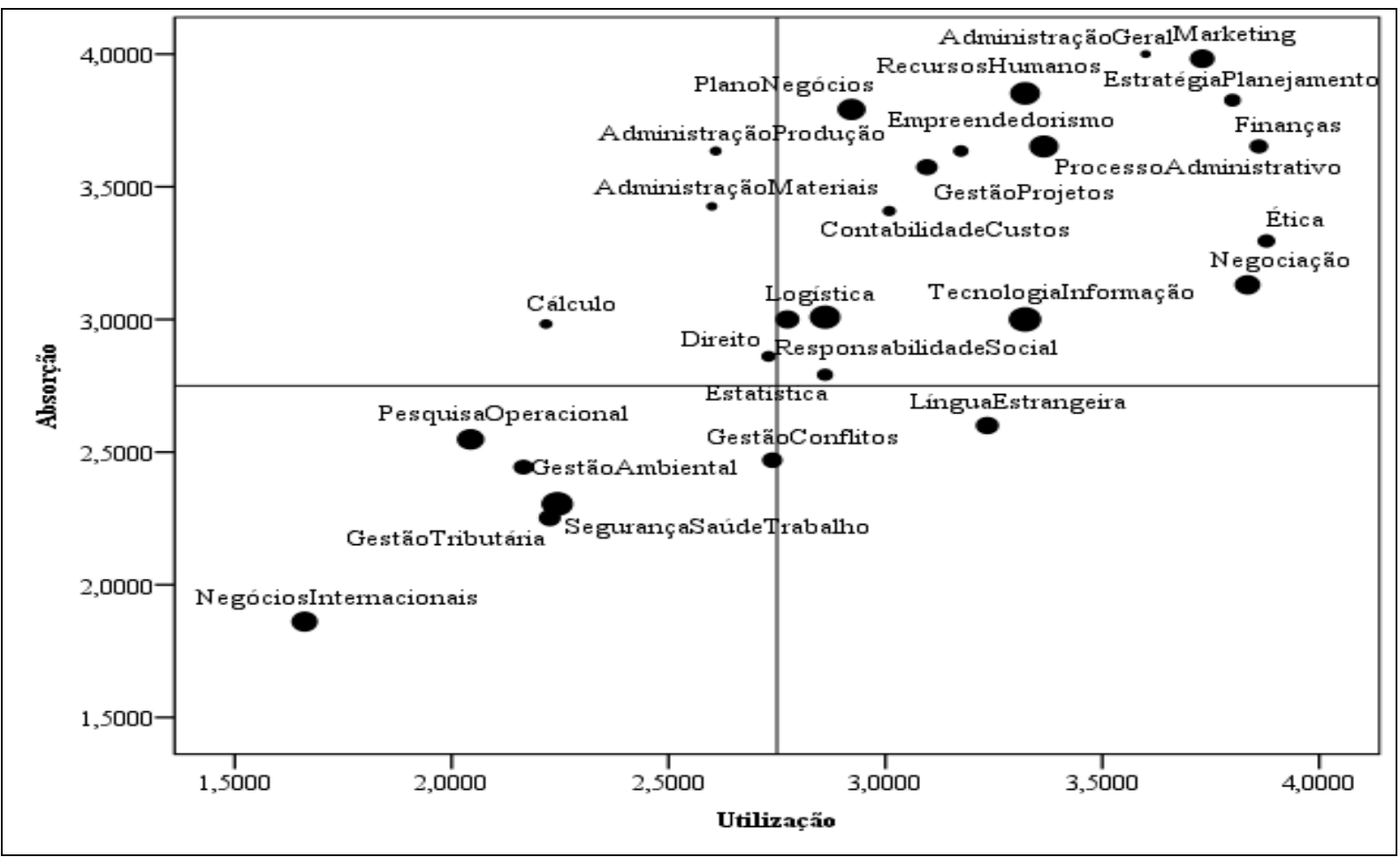

Gráfico 5 Utilização e absorção média dos conhecimentos

Fonte: Elaborado pelos autores, a partir dos dados coletados na pesquisa de campo.

A fim de melhor analisar as semelhanças entre as disciplinas, acerca dos três construtos observados (conhecimento, importância e utilização), construiu-se um mapa perceptual, através do escalonamento multidimensional replicado, sendo este observado no Gráfico 6.

A seleção do número mínimo de dimensões necessárias para reproduzir de forma parcimoniosa as semelhanças entre as disciplinas foi feita por observação do Scree-plot e dos gráficos das proximidades transformadas versus distâncias, conforme descrito em Maroco (2007). A qualidade do modelo foi avaliada por recurso à dispersão das proximidades explicada pela solução retida (DAF), dado por 1 - NRS, em que NRS é o Raw Stress Normalizado, medida minimizada pelo algoritmo PROXSCAL. Assim, de acordo com o exposto pelo autor, o DAF $=0,87304$, encontrado no mapa, é considerado bom.

De acordo com o mapa perceptual, e tendo em conta a análise de agrupamentos aplicada aos escores das disciplinas nas duas dimensões determinadas pelo escalonamento multidimensional, são formados quatro grandes grupos de disciplinas que apresentam maior semelhança entre si. São eles: Grupo 1 - Administração de Materiais, Administração da Produção, Contabilidade de Custos, Processo Administrativo, Cálculo e Estatística; Grupo 2 Gestão de Conflitos, Negócios Internacionais, Gestão Ambiental, Direito, Gestão Tributária, 
Pesquisa Operacional, Segurança e Saúde no Trabalho; Grupo 3 - Tecnologia da Informação, Responsabilidade Social, Língua Estrangeira, Negociação e Ética; Grupo 4 - Logística, Plano de Negócios, Gestão de Projetos, Finanças, Recursos Humanos, Administração Geral, Empreendedorismo, Estratégia e Planejamento e Marketing.

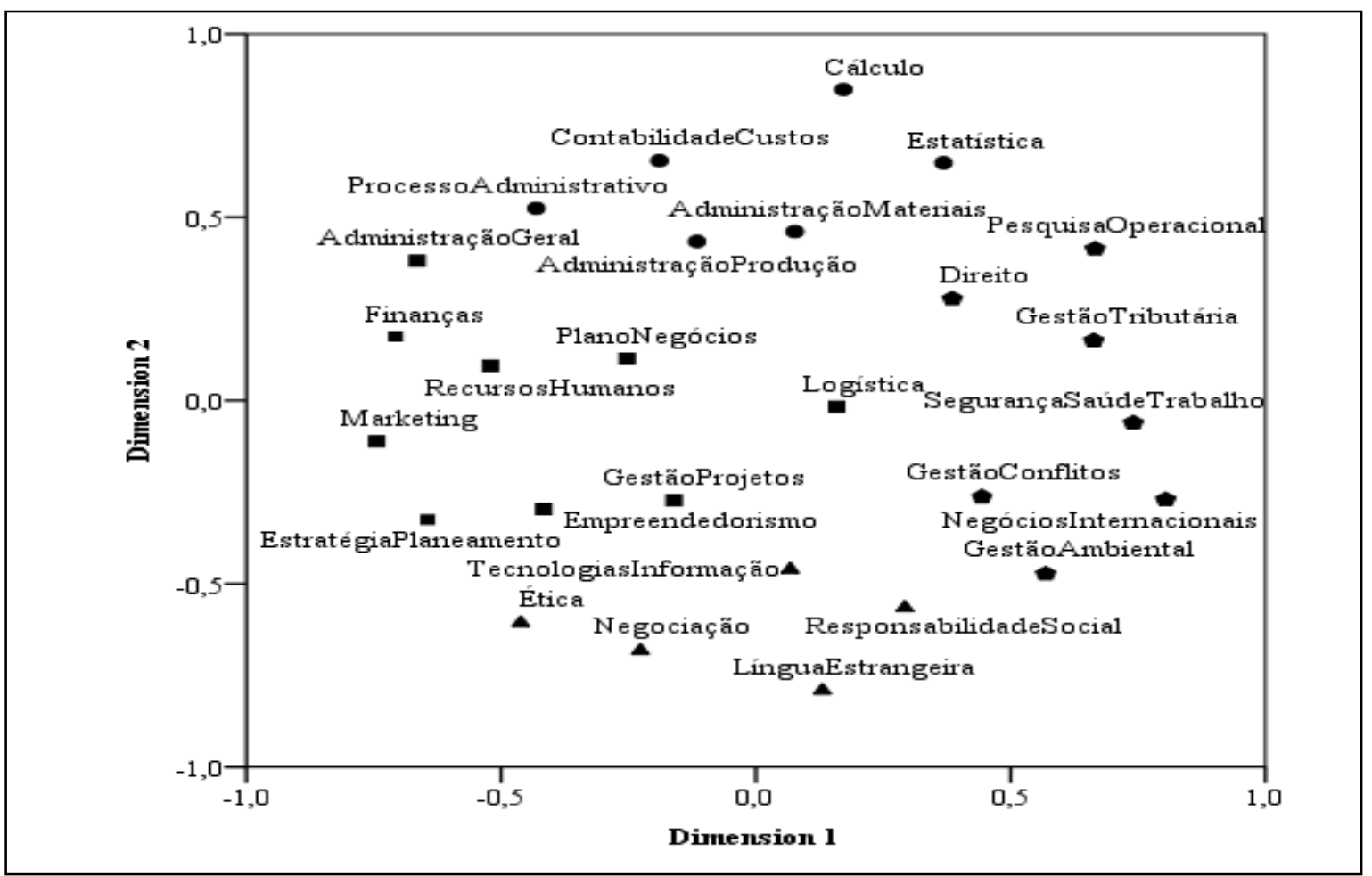

Gráfico 6 Mapa perceptual das semelhanças entre os conhecimentos

Fonte: Elaborado pelos autores, a partir dos dados coletados na pesquisa de campo.

Analisando-se os grupos através das médias dos construtos, tem-se que: o grupo 1 é formado por disciplinas que tem uma predominância de média aplicação, alto conhecimento e utilização entre média e alta, sendo a disciplina da Cálculo a única a ter baixa aplicação e a ter baixa importância, juntamente com a disciplina de Estatística. Ressalta-se que todas as disciplinas deste grupo são disciplinas obrigatórias da grade curricular do curso de Administração da universidade pesquisada, justificando o conhecimento ser avaliado entre médio a alto.

O grupo 2 é formado por disciplinas de baixa a média aplicação e importância, e baixo conhecimento, sendo a disciplina de Negócios Internacionais a única que tem um construto (importância) considerado alto. Tal grupo constitui-se, em sua maioria, de disciplinas que não fazem parte da grade do curso da Universidade Federal do Ceará, justificando o baixo 
conhecimento acerca das mesmas. Sugere-se, portanto, a inserção destas disciplinas, com destaque para a disciplina de Negócios Internacionais.

O grupo 3 é formado por conhecimentos de alta aplicação e importância, e de conhecimento médio a alto. Apesar da maioria das disciplinas não serem contempladas na grade do curso de Administração da UFC, são temas tratados em outras disciplinas e também temas de discussão recorrente nos dias de hoje (Ética, Responsabilidade Social, Tecnologia). Assim, o bom conhecimento dos egressos acerca de tais disciplinas vem, em sua maioria, de fontes outras ao invés da Universidade, sugerindo-se a inserção ou reforço destas disciplinas na grade do curso estudado. Observa-se que os grupos 2 e 3 são os que apresentam maior déficit de absorção em relação à aplicação e importância de seus conhecimentos, devendo tais grupos recebe maior atenção do curso pesquisado, a fim de sanar tais deficiências.

O grupo 4 é formado por disciplinas de alta aplicação e conhecimento, e alta a média importância. Em todas as disciplinas do grupo, o nível de conhecimento é igual ou superior ao nível de aplicação, não gerando assim déficits para os egressos. Todas as disciplinas do grupo fazem parte da grade curricular do curso pesquisado, seja como disciplinas obrigatórias ou habilitações da mesma, como temas tratados em outras disciplinas (Gestão de Projetos e Estratégia e Planejamento).

\section{CONCLUSÃO}

Os resultados encontrados neste estudo podem ajudar a melhorar a grade curricular do curso de Administração da Universidade pesquisada, pois refletem a percepção dos egressos do curso que em sua maioria já estão no mercado de trabalho.

As evidências empíricas encontradas apontam convergências dos grupos de disciplinas Administração da Produção e Administração de Materiais nos três construtos analisados, indicando similaridade entre os construtos. Os conhecimentos considerados menos importantes pelos egressos foram também conhecimentos que os mesmos responderam que menos utilizam - Cálculo e Saúde e Segurança no Trabalho. Alguns conhecimentos relatados pelos alunos se mostraram pertinentes para inserção na grade curricular do curso, como Negociação, Negócios Internacionais, Gestão Ambiental e Responsabilidade Social.

A área de Finanças, Planejamento Estratégico, Administração Geral, e Marketing foram as melhor pontuadas nos três construtos (importância, conhecimento e utilização), o que indica um ponto positivo para o curso. Percebe-se ainda uma carência de algumas outras 
disciplinas consideradas importantes na grade curricular do curso de Administração da UFC, como Ética e reforço na área de Tecnologia da Informação.

Limitações neste estudo devem ser consideradas. Sugere-se para pesquisas futuras analisar através da modelagem de equações estruturais a relação entre os três construtos desta pesquisa de forma a constatar se a importância dada aos conhecimentos explorados implica em um maior grau de absorção e utilização por parte dos alunos, ou se a utilização dos conhecimentos tratados neste trabalho é que implica em uma maior percepção de importância, ou se ainda o grau de absorção influencia a importância e a utilização dos conhecimentos.

\section{REFERÊNCIAS}

AKTOUF, O. Ensino de Administração: por uma pedagogia para a mudança. Revista Organizações e Sociedades, v. 12, n. 35, p.152-159, 2005.

ALVARÃES, A. C. T. A formação geral de estudantes do curso de Administração de Empresas: propostas a partir das constatações do ENADE. In: ENCONTRO ANUAL DOS PROGRAMAS DE PÓS-GRADUAÇÃO EM ADMINISTRAÇÃO, 33, 2009, São Paulo. Anais...São Paulo: ANPAD, 2009.

ALVES, F. M. S.; REINERT, J. N. Percepção dos coordenadores dos cursos de graduação da UFSC sobre a multidisciplinaridade dos cursos que coordenam. Revista Avaliação, v.12, n. 4, p. 685-702, dez. 2007.

ARAÚJO, M. A.D.; CORREIA, A. C. Uma Avaliação do Processo Formativo do Administrador: um Estudo de Caso em uma Instituição de Ensino Superior. In: ENCONTRO ANUAL DOS PROGRAMAS DE PÓS-GRADUAÇÃO EM ADMINISTRAÇÃO, 25, 2001, Campinas. Anais...Campinas: ANPAD, 2001.

BOMTEMPO, M. S.; SILVA, D.; GARCIA, M. N.; CODA, R. Estudo dos Motivos da Escolha do Curso de Administração de Empresa por meio da Modelagem de Equação Estruturais. In: ENCONTRO ANUAL DOS PROGRAMAS DE PÓS-GRADUAÇÃO EM ADMINISTRAÇÃO , 31, 2007, Rio de Janeiro. Anais...Rio de Janeiro: ANPAD, 2007.

CFA - Conselho Federal de Administração. Sitio oficial. Disponível em:

$<$ http://www.cfa.org.b r/html/c_gestor/Par433_93.pdf >. Acesso em: 16 de dez. 2011.

COOPER, D. R.; SCHINDLER, P. S. Métodos de pesquisa em administração. Porto Alegre: Bookman, 2003.

CORRAR, L. J; PAULO, E; DIAS FILHO, J. M. Análise multivariada: para os cursos deadministração, ciências contábeis e economia. Atlas: São Paulo, 2009.

COSTA, F. K.; PEREIRA, F. de A.; SOLINO, A. da S. Uma Percepção Curricular dos Egressos para a Formação de Pós-Graduação em Administração segundo a Análise 
Proporcional do Discurso. In: ENCONTRO ANUAL DOS PROGRAMAS DE PÓSGRADUAÇÃO EM ADMINISTRAÇÃO, 25, 2001, Campinas. Anais...Campinas: ANPAD, 2001.

DIAS, R. O ensino flexível: a perspectiva de adoção de maior flexibilidade no Ensino dos cursos de administração. Revista Brasileira de Docência, Ensino e Pesquisa em Administração, v. 1, n. 1, p.65-81, mai. 2009.

FEAAC. Sítio oficial. Disponível em: $<$ http://www.feaac.ufc.br/index.

php?option=com_content\&task=view\&id=29\&Itemid=39)>. Acesso em: 02 de dez. 2011.

FISCHER, T. Alice através do espelho ou Macunaíma em Campus Papagalli ? Mapeando rotas de ensino dos estudos organizacionais no Brasil. Revista Organizações e Sociedade, v.10, n.28, ago./dez. 2003.

GODOY, A. S.; ANTONELLO C. S.; BIDO D. S.; SILVA, D. Um Estudo de Modelagem de Equações Estruturais para a Avaliação das Competências de Alunos do Curso de Administração. In: ENCONTRO ANUAL DOS PROGRAMAS DE PÓS-GRADUAÇÃO EM ADMINISTRAÇÃO, 30, 2006, Salvador. Anais...Salvador: ANPAD 2006.

HAIR JR, J. F. et al. Análise multivariada de dados. 5.ed., Porto Alegre: Bookman, 2005.

KITAHARA, J. R.; GOUVÊA, M. A.; PETRONI, L. M.; PLANTULLO, V. L. Nível de percepção dos alunos egressos de um curso de Administração sobre a adequação do currículo às atividades profissionais. Revista de Gestão USP, v. 15, n. 1, jan./mar. 2008.

MACEDO, E. F. Novas tecnologias e currículo. In: MOREIRA, A. F. B. Currículo: questões atuais. 12. ed., Campinas: Papirus, 2006, p.39-58.

MACIEL, C. O.; HOCAYEN-DA-SILVA, A. J.; CASTRO, M. O ideário de escola na ótica dos docentes: pura subjetividade ou padrões estruturados de cognição nos cursos de Administração? Revista de Administração Contemporânea, v.12, n. 3, p.659-688, jul./set. 2008.

MARANHÃO, C. M. S. A; DE PAULA, A. P. P. Reflexões sobre a indústria cultural e o ensino em Administração. Revista Brasileira de Docência, Ensino e Pesquisa em Administração,v. 1, n. 2, p.159-176, jul. 2009. Edição especial.

MAROCO, J. Análise estatística com utilização do SPSS. 3.ed., Lisboa: Edições Sílabo,2007.

MINISTÉRIO DA EDUCAÇÃO - MEC. Avaliação externa das instituições de educação superior. Brasília, Ministério da Educação, 2006a, 180p.

da Educação, 2006b. 118p

Instrumento de avaliação de cursos de graduação. Brasília, Ministério 
MOREIRA, A. F.; SILVA, T. T.Currículo, cultura e sociedade. 3.ed., São Paulo: Cortez, 1999.

NICOLINI, A. Qual será o futuro das fábricas de administradores? Revista de Administração de Empresas, v. 43, n.2, p. 44-54, 2003.

PATRICIO RIBEIRO, L. A. Faculdade de Ciências Econômicas do Ceará: incursão histórica - 1938-2000. Fortaleza: Edições UFC, 2001.

PRESTES MOTTA, F. A questão da formação do Administrador. Revista de Administração deEmpresas, v. 23, n. 4, p. 53-55, out./dez. 1983.

SAMPIERI, R. H.; COLLADO, C. F.; LUCIO, P. B. Metodologia de pesquisa.3 ed.,São Paulo: McGraw-Hill, 2006.

SAVIANI, N. Saber escolar, currículo e didática: problemas da unidade conteúdo/método no processo pedagógico. Campinas: Autores Associados, 1994.

SILVA, M. R.; FISCHER, T. Ensino de Administração: Um Estudo da Trajetória Curricular de Cursos de Graduação.In: ENCONTRO ANUAL DOS PROGRAMAS DE PÓS-

GRADUAÇÃO EM ADMINISTRAÇÃO, 32, 2008, Rio de Janeiro. Anais...Rio de Janeiro: ANPAD, 2008.

SKORA, C. M.; MENDES, D.As Coisas Novas: Por que a TGA parou no tempo?In: ENCONTRO ANUAL DOS PROGRAMAS DE PÓS-GRADUAÇÃO EM ADMINISTRAÇÃO, 25, 2001, Campinas.Anais...Campinas: ANPAD, 2001.

SOBRINHO, J. D. Avaliação da educação superior. 1.ed., Petrópolis: Vozes, 2000.

SOUZA, S. A.; REINERT, J. N. Motivação para entrada e permanência nos cursos de graduação emAdministração da Universidade Federal de Mato Grosso do Sul. In:

ENCONTRO ANUAL DOS PROGRAMAS DE PÓS-GRADUAÇÃO EM ADMINISTRAÇÃO, 33, 2009, São Paulo. Anais...São Paulo: ANPAD, 2009. 